University of Nebraska - Lincoln

DigitalCommons@University of Nebraska - Lincoln

Transient groundwater chemistry near a river: Effects on $\mathrm{U}(\mathrm{VI})$ transport in laboratory column experiments

Jun Yin

Oregon State University

Roy Haggerty

Oregon State University

Deborah L. Stoliker

U.S. Geological Survey

Douglas B. Kent

U.S. Geological Survey

Jonathan D. Istok

Oregon State University

See next page for additional authors

Follow this and additional works at: https://digitalcommons.unl.edu/usdoepub

Part of the Bioresource and Agricultural Engineering Commons

Yin, Jun; Haggerty, Roy; Stoliker, Deborah L.; Kent, Douglas B.; Istok, Jonathan D.; Greskowiak, Janek; and Zachara, John M., "Transient groundwater chemistry near a river: Effects on $\mathrm{U}(\mathrm{VI})$ transport in laboratory column experiments" (2011). US Department of Energy Publications. 308.

https://digitalcommons.unl.edu/usdoepub/308

This Article is brought to you for free and open access by the U.S. Department of Energy at DigitalCommons@University of Nebraska - Lincoln. It has been accepted for inclusion in US Department of Energy Publications by an authorized administrator of DigitalCommons@University of Nebraska - Lincoln. 


\section{Authors}

Jun Yin, Roy Haggerty, Deborah L. Stoliker, Douglas B. Kent, Jonathan D. Istok, Janek Greskowiak, and John M. Zachara 


\title{
Transient groundwater chemistry near a river : Effects on U(VI) transport in laboratory column experiments
}

\author{
Jun Yin, ${ }^{1}$ Roy Haggerty, ${ }^{1}$ Deborah L. Stoliker, ${ }^{2}$ Douglas B. Kent, ${ }^{2}$ Jonathan D. Istok, ${ }^{3}$ Janek Greskowiak, ${ }^{4,5}$ \\ and John M. Zachara ${ }^{6}$
}

Received 27 March 2010; revised 2 December 2010; accepted 18 January 2011; published 5 April 2011.

[1] In the 300 Area of a U(VI)-contaminated aquifer at Hanford, Washington, USA, inorganic carbon and major cations, which have large impacts on U(VI) transport, change on an hourly and seasonal basis near the Columbia River. Batch and column experiments were conducted to investigate the factors controlling U(VI) adsorption/desorption by changing chemical conditions over time. Low alkalinity and low Ca concentrations (Columbia River water) enhanced adsorption and reduced aqueous concentrations. Conversely, high alkalinity and high $\mathrm{Ca}$ concentrations (Hanford groundwater) reduced adsorption and increased aqueous concentrations of $\mathrm{U}(\mathrm{VI})$. An equilibrium surface complexation model calibrated using laboratory batch experiments accounted for the decrease in U(VI) adsorption observed with increasing (bi)carbonate concentrations and other aqueous chemical conditions. In the column experiment, alternating pulses of river and groundwater caused swings in aqueous $\mathrm{U}(\mathrm{VI})$ concentration. A multispecies multirate surface complexation reactive transport model simulated most of the major U(VI) changes in two column experiments. The modeling results also indicated that $\mathrm{U}(\mathrm{VI})$ transport in the studied sediment could be simulated by using a single kinetic rate without loss of accuracy in the simulations. Moreover, the capability of the model to predict U(VI) transport in Hanford groundwater under transient chemical conditions depends significantly on the knowledge of real-time change of local groundwater chemistry.

Citation: Yin, J., R. Haggerty, D. L. Stoliker, D. B. Kent, J. D. Istok, J. Greskowiak, and J. M. Zachara (2011), Transient groundwater chemistry near a river: Effects on U(VI) transport in laboratory column experiments, Water Resour. Res., 47, W04502, doi:10.1029/ 2010WR009369.

\section{Introduction}

[2] Uranium pollution of groundwater stems from all aspects of the nuclear fuel and weapons cycle, from mining through final disposal. USA facilities for weapons production cover $>8000 \mathrm{~km}^{2}$ [National Research Council, 2000], and have generated $1.7 \times 10^{9} \mathrm{~m}^{3}$ of liquid waste, most of which was discharged to the subsurface [Crowley and Ahearne, 2002]. Because of the need for water in many of the industrial processes utilized in fuel and weapons productions, facilities and associated contaminated groundwater and sediment are frequently located close to streams and rivers, and groundwater/river water interactions can generate diel and seasonal changes in groundwater chemistry and flux. The U.S. Department of Energy's 300-FF-5

\footnotetext{
${ }^{1}$ Department of Geosciences, Oregon State University, Corvallis, Oregon, USA.

${ }^{2}$ U.S. Geological Survey, Menlo Park, California, USA.

${ }^{3}$ Department of Civil Engineering, Oregon State University, Corvallis, Oregon, USA

${ }^{4}$ CSIRO Land and Water, Wembley, Western Australia, Australia.

${ }^{5}$ Working group Hydrogeology and Landscape Hydrology, Institute for Biology and Environmental Sciences, Carl von Ossietzky University of Oldenburg, Oldenburg, Germany.

${ }^{6}$ Pacific Northwest National Laboratory, Richland, Washington, USA.
}

Copyright 2011 by the American Geophysical Union. 0043-1397/11/2010WR009369
Operable Unit ("300 Area") at the Hanford site near Richland, WA is a good example. The site is bounded to the east by the Columbia River where the river stage oscillates with an amplitude of up to $1 \mathrm{~m} / \mathrm{d}$ and $>2 \mathrm{~m}$ per season [Lindberg and Peterson, 2004; Zachara et al., 2005]. Due to very high hydraulic conductivity of adjacent aquifers, river stage oscillations cause changes in groundwater flux on a diel basis, and in groundwater chemistry on a seasonal basis over $250 \mathrm{~m}$ from the river [Hammond and Lichtner, 2010]. These changes have significant impacts on transport of solutes such as uranium.

[3] Diel and seasonal stage changes in streams all over the world generate oscillatory subsurface water chemistry in the hyporheic zone and perirheic zones. The scale of the groundwater oscillations is, in most cases, smaller than at Hanford. However, there are commonly large differences in chemistry (redox, $\mathrm{pH}$, alkalinity, organic carbon, etc.) between surface water and adjacent groundwater. The oscillations of these chemical differences have nonlinear and unintuitive consequences on riparian groundwater transport in many streams [Jacobs et al., 1988; von Gunten et al., 1991; Conant et al., 2004]. In this way, the changes in groundwater chemistry in the 300 Area are probably replicated at smaller scales in many hyporheic and perirheic zones.

[4] In the 300 Area (Figure 1), the transport of aqueous $\mathrm{U}(\mathrm{VI})$ is retarded because of adsorption and precipitation along the flow path [Davis et al., 2004; McKinley et al., 




Figure 1. Integrated Field Research Challenge (IFRC) site in the 300 Area at Hanford, WA.

2006]. These adsorption and precipitation processes are significantly influenced by water chemistry variations [Turner et al., 1996; Fritz and Arntzen, 2007; Ma et al., 2010; Hammond and Lichtner, 2010]. In situ measurement of water chemistry shows that $\mathrm{pH}$ in both Hanford groundwater and Columbia River water differs by around 1 unit depending on season and location. However, (bi)carbonate and other major ion concentrations in each water type remain relatively constant. The differences in chemical composition between groundwater and river water have important effects on the transport of U(VI) [Wellman et al., 2008; Bond et al., 2008]. In general, the lower (bi)carbonate concentration $(1.13 \mathrm{mmol} / \mathrm{L}$ in river water versus 2.57 $\mathrm{mmol} / \mathrm{L}$ in groundwater) and lower $\mathrm{Ca}$ concentration $(0.45$ $\mathrm{mmol} / \mathrm{L}$ in river water versus $1.21 \mathrm{mmol} / \mathrm{L}$ in groundwater) of the Columbia River water drives more extensive U(VI) adsorption and retardation [Ma et al., 2010]. Therefore understanding U(VI) adsorption/desorption under transient chemical conditions is essential for understanding and predicting U(VI) transport in the 300 Area.

[5] Several studies [e.g., Liu et al., 2004; McKinley et al., 2006] have evaluated U(VI) adsorption/desorption and precipitation/dissolution mechanisms at the microscale using purified specimen minerals and sediments from the 300 Area. Bond et al. [2008] used artificial groundwaters to extract labile U(VI) from vadose zone sediments, and the results showed that the release of U(VI) depends strongly on chemistry, particularly alkalinity, which can, in turn, be affected by the general chemistry of the sediment-water mixture. Liu et al. [2009] also showed that U(VI) desorption varies with aqueous chemistry. The rate of U(VI) desorption is controlled by coupled intraparticle diffusion and adsorption, likely along a wide range of diffusion path lengths. This has been successfully modeled by assuming redistribution between slow and fast reactive sites [Qafoku et al., 2005; Liu et al., 2008; Wellman et al., 2008]. From the perspective of a field-scale reactive transport model that can be used to simulate the U(VI) plume transport at the 300 Area, these effects can be assessed by changing the flow velocity and chemical composition in the modeling domain. Both of these changes are typical consequences of Columbia River stage changes. Medium-scale column (on the order of $1 \mathrm{~m}$ ) experiments provide opportunities to understand the U(VI) transport behavior under conditions closer to those observed in the field, but with controlled boundary conditions and high-resolution measurements. Qafoku et al. [2005] and Liu et al. [2008] conducted such column experiments to investigate U(VI) desorption and adsorption under a variety of flow rates and physical properties using size-fractionated and field-texture sediments. These experiments were conducted under constant water chemistry. Liu et al. [2008] successfully modeled U(VI) desorption from 300-Area sediment using a surface complexation model coupled to a dualdomain mass transfer and multirate kinetics model with a lognormal distribution of rate coefficients.

[6] The surface complexation and multirate kinetics model have been incorporated into two field-scale models developed with the 3-D multicomponent reactive transport codes PHT3D [Prommer et al., 2003] and PFLOTRAN [Hammond et al., 2008], respectively. Using PHT3D, Ma et al. [2010] predicted that aqueous U(VI) concentrations near the river would vary with flow direction because of changes in water chemistry. Using PFLOTRAN, Hammond and Lichtner [2010] showed that, under present-day conditions, transient chemistry and groundwater flow should generate an effect in which U(VI) can move toward the river with low retardation, but U(VI) transport away from the river is highly retarded. One challenge with these models is that, because transport is expected to be very sensitive to the details of water chemistry, it is difficult to know if the predictions are accurate. Furthermore, the multirate surface complexation approach to modeling the complex sets 
of processes causing the observed rate-limited U(VI) desorption has not been evaluated in the presence of strongly variable chemical conditions influencing U(VI) retardation.

[7] In this paper, we examine U(VI) desorption under variable chemical conditions in laboratory batch and column experiments on sediments collected from the deep vadose zone/upper saturated zone at the Integrated Field Research Challenge (IFRC) site (Figure 1) in the 300 Area at Hanford, USA. Two aqueous solutions similar to Hanford groundwater and Columbia River water were used to drive the $\mathrm{U}(\mathrm{VI})$ adsorption-desorption in the column experiments. There are two results from this paper. First, from batch experiments in well-mixed reactors, we demonstrate the impact of groundwater chemistry on adsorptiondesorption reactions, thereby deriving a sediment specific surface complexation model. Second, we utilize the developed surface complexation model and test its suitability in the distributed rate kinetic context to describe diffusionlimited adsorption-desorption under variable chemical conditions in flow-through column experiments.

\section{Methods}

\subsection{Sediment Characterization}

[8] Sediment was collected from bore holes prior to installation of wells for the IFRC tracer test site (Figure 1). The following types of sediment samples were composited: 19 grab samples from 15 well locations, 9 discreet-depth samples from 6 well locations where continuous cores were collected; and 8 discreet-depth samples from locations where discreet-depth wells were installed (Figure 1). These samples were collected immediately above and below the water table, which is a hydraulically dynamic zone where the water table oscillates in response to the Columbia River water stage changes. The zone from 7.5 to $10.5 \mathrm{~m}$ below ground surface, commonly referred to as the "smear zone," contains the highest concentrations of U(VI) associated with the solid phase, and it is hypothesized that the uranium was placed there by adsorption and precipitation of uranium located in the upper part of the saturated zone [Zachara et al., 2005]. During the time period when the water table rises, either adsorption or desorption occurred depending on the in situ groundwater chemical conditions. Therefore sediments in the smear zone become both a source and a sink of U(VI) [Qafoku et al., 2005]. All sediment is from the Hanford Formation, composed of a poorly sorted mixture of clay through cobbles, dominated by pebbles $(2-64 \mathrm{~mm})$. Prior to the batch and column experiments, all 36 samples were mixed, dried, homogenized, weighed (456 kg total), and then sieved to $<2 \mathrm{~mm}(22.4 \%$ by mass $)$. The $<2 \mathrm{~mm}$ fraction contains most of the sorbed U(VI) associated with carbonate minerals, clays, and micas [Zachara et al., 2005; Liu et al., 2008]. X-Ray diffraction analysis showed that all size fractions had similar mineralogical composition: quartz $(>25 \%)$, plagioclase $(5-25 \%)$, and pyroxene $(<5 \%)$. Dominant plagioclase compositions are Na-anorthite, albite, and labradorite. Dominant pyroxenes are augite, diopside, and pigeonite. Minor amounts of poorly ordered illite and kaolinite, and very poorly ordered smectite (likely $15 \AA$ montmorillonite) were observed in most size fractions. Carbonates are a trace component of the $<2 \mathrm{~mm}$ fraction, but have a sig- nificant impact on the water and U(VI) chemistry [Zachara et al., 2005].

[9] Total U was measured by $\gamma$-spectrometry using nondestructive measurement of the $63 \mathrm{keV}$ line of ${ }^{234} \mathrm{Th}$ in secular equilibrium with ${ }^{238} \mathrm{U}$. The specific surface area was measured by $\mathrm{N}_{2}$ adsorption at $77.35 \mathrm{~K}$ at 1.0 atm (Micromeritics Tristar 3000). As a check, a sample was sent to Quantachrome (Boynton Beach, FL) for a duplicate measurement. Labile U(VI) was calculated using a (bi)carbonate extraction following the method of Kohler et al. [2004]. Sediment $(50 \mathrm{~g} / \mathrm{L})$ was reacted with a solution consisting of $1.44 \times 10^{-2} \mathrm{M} \mathrm{NaHCO}_{3}$ and $2.8 \times 10^{-3} \mathrm{M} \mathrm{Na}_{2} \mathrm{CO}_{3}$ at $\mathrm{pH}$ 9.5 and an alkalinity of $20 \mathrm{meq} / \mathrm{L}$. The duplicate $250 \mathrm{~mL}$ reaction vessels were shaken on an orbital shaker table and subsampled ( $3 \mathrm{~mL}$ ) for up to 56 weeks. Bicarbonate extraction samples were analyzed for $\mathrm{pH},[\mathrm{U}(\mathrm{VI})]$, and major cation concentrations. In the following sections, we assume that the labile fraction of U(VI) consists of only adsorbed U(VI) [Davis et al., 2004; Kohler et al., 2004].

[10] The $<2 \mathrm{~mm}$ fraction is $85.4 \%$ sand $(>62.5 \mu \mathrm{m})$ and $14.6 \%$ undifferentiated silt and clay. The total U concentration in the sediment is $1.2 \pm 0.1 \times 10^{-8} \mathrm{~mol} / \mathrm{g}$. The measured adsorbed $U$ concentration in the sediment is $4.39 \times$ $10^{-9} \mathrm{~mol} / \mathrm{g}$. The average specific surface area determined by four samples is $14.1 \pm 1.6 \mathrm{~m}^{2} / \mathrm{g}$. Samples sent for analysis by an external laboratory measured $22 \%$ higher in surface area than those measured internally. This difference is not abnormal for lab-to-lab comparison of surface areas and all four measurements were averaged for use in modeling. Assuming a site density of $3.84 \mu \mathrm{mol} / \mathrm{m}^{2}$ [Davis and Kent, 1990], the adsorption site concentration used in model calculations is $5.4 \times 10^{-5} \mathrm{~mol} / \mathrm{g}$.

\subsection{Batch Experiments}

[11] Electrolyte solutions mimicking field-measured solution concentrations in 300 Area groundwaters, referred to as synthetic groundwater (SGW-B1, -B2, -B3, -B4, and $\mathrm{B} 5$, Table 1), were prepared and mixed with sediment in batch reactors at suspension densities of $100 \mathrm{~g} / \mathrm{L}$ (SGW-B1, -B2, and -B3) and $1000 \mathrm{~g} / \mathrm{L}$ (SGW-B3, -B4, and -B5). All synthetic groundwater solutions described herein were free of $U$ unless otherwise noted. The synthetic groundwaters

Table 1. Major Chemical Composition of Synthetic Hanford Groundwater (SGW) and Synthetic Columbia River Water $(\mathrm{SCRW})(\mathrm{mmol} / \mathrm{L})^{\mathrm{a}}$

\begin{tabular}{lcccccc}
\hline & $\mathrm{Ca}^{2+}$ & $\mathrm{Mg}^{2+}$ & $\mathrm{SO}_{4}^{2-}$ & $\mathrm{NO}_{3}^{-}$ & Alkalinity (meq/L) & $\mathrm{pH}$ \\
\hline SGW-B1 & 0.5 & 0.5 & 2.2 & 2.2 & 0.5 & 7.77 \\
SGW-B2 & 0.5 & 0.5 & 2.1 & 1.7 & 1.0 & 8.12 \\
SGW-B3 & 0.5 & 0.5 & 2.0 & 1.2 & 2.0 & 8.06 \\
SGW-B4 & 0.5 & 0.5 & 1.5 & 0.95 & 4.0 & 8.09 \\
SGW-B5 & 0.5 & 0.4 & 1.4 & 1.0 & 6.0 & 8.11 \\
SGW-0 & 1 & 0.51 & 0.64 & 0.47 & 1.57 & 7.9 \\
SGW-1 & 1 & 0.51 & 0.64 & 0.47 & 1.97 & 8.37 \\
SGW-2 & 1 & 0.51 & 0.64 & 0.47 & 1.56 & 8.37 \\
SGW-3 & 1 & 0.51 & 0.64 & 0.47 & 1.66 & 7.7 \\
SGW-4 & 1 & 0.51 & 0.64 & 0.47 & 1.44 & 7.8 \\
SCRW & 0.25 & 0.17 & 0.1 & 0.1 & 0.66 & 7.5 \\
\hline
\end{tabular}

${ }^{\text {a}} \mathrm{SGW}-\mathrm{B} 1, \mathrm{~B} 2, \mathrm{~B} 3, \mathrm{~B} 4, \mathrm{~B} 5$ : Synthetic groundwater used in batch experiments. SGW0: Synthetic groundwater used in column experiment. SGW1/ SGW2/SGW3/SGW4: Synthetic groundwaters used in column experiment modeling. SCRW: Synthetic river water used in column experiment. 
each contained the same concentration of $\mathrm{Ca}, \mathrm{K}$, and $\mathrm{Mg}$ while alkalinity was varied between 0.5 and $6 \mathrm{meq} / \mathrm{L}$. Sodium salts were added to maintain an ionic strength of $0.01 \mathrm{M}$. For each kinetic time point, duplicate sealed reaction tubes $(50 \mathrm{~mL}$ for $100 \mathrm{~g} / \mathrm{L}$ and $15 \mathrm{~mL}$ for $1000 \mathrm{~g} / \mathrm{L})$ were mixed on end-over-end rotators and sacrifice sampled between 1 and 293 days. At the time of sampling, pH was measured, the supernatant filtered $(0.45 \mu \mathrm{m})$, and alkalinity titrations performed. A subsample of the filtered supernatant was analyzed for $\mathrm{U}(\mathrm{VI})$ and major cation concentrations.

\subsection{Column Experiments}

[12] Additional electrolyte solutions were prepared to represent the Hanford groundwater (SGW0) and Columbia River water (SCRW, Table 1) for column experiments. Compositions of these two electrolyte solutions were calculated from in situ water chemistry and are based on a set of common "recipes" (C. Liu and J. McKinley, personal communication, 2009). Both electrolyte solutions were free of U. A $25 \mathrm{mg} / \mathrm{L} \mathrm{Br}$ solution was also prepared for the conservative tracer test based on the recipe of SGW-0.

[13] The same sediment used in the batch experiment was packed into two $50 \mathrm{~cm}$ by $5 \mathrm{~cm}$ ID stainless steel columns. The first column was packed in $5 \mathrm{~cm}$ increments of dry sediment. After each increment, the column was tapped on the outside with a mallet to make sure the sediment was tightly packed. At each end, stainless steel screens, O-rings, and column ends were secured using $16.5 \mathrm{~mm}$ bolts on a flange. After packing, SGW was slowly injected upward into the column to bring it to saturation. The column then was left overnight. Before starting the desorption experiment, a small volume of SGW was injected into the column to fill any pores that were occupied by air during the initial injection. In the second column, before adding dry sediment at each increment, approximately $20 \mathrm{~mL}$ of SCRW was pumped into the column. The top level of the added sediment was kept just below the water table. Both of the empty columns, the added sediment in each column, and both of the saturated columns were weighed. The difference between the saturated column and the dry column was used as the pore volume.

[14] A high-performance liquid chromatography (HPLC) pump was used to inject the solution into the column. A 276 $\mathrm{kPa}$ back pressure regulator was used between the HPLC pump and the column inlet to minimize disturbance of the pumping rate resulting from pressure oscillations in the column. The outlet of the column was connected to a Gilson 212 auto sampler. An inline flow-through $\mathrm{pH}$ probe (Microelectrodes, Bedford, $\mathrm{NH}$ ) was used to measure the effluent $\mathrm{pH}$. The pumping rate was maintained at $1 \mathrm{~mL} / \mathrm{min}$ in all experiments.

[15] Two U(VI) desorption experiments were conducted. (1) Desorption experiment (Deso1). This experiment was conducted in the dry-packed column. SGW-0 was eluted through the column to leach the U(VI). Over 40 pore volumes were injected through the column to bring the aqueous $\mathrm{U}(\mathrm{VI})$ concentration to below $30 \mu \mathrm{g} / \mathrm{L}$ (drinking water standard). Three stop-flow events (with lengths of 24, 84, and $132 \mathrm{~h}$ ) were conducted to evaluate $\mathrm{U}(\mathrm{VI})$ desorption kinetics when advection stops. The length of the stop flows were chosen to probe different time scales of mass transfer and desorption, and the timing of the stop flows were determined by work schedules. During the stop flow, it is expected that the nonequilibrium between the sorbed $\mathrm{U}(\mathrm{VI})$ phases and pore water causes changes to aqueous $\mathrm{U}(\mathrm{VI})$ concentrations. (2) Transient chemistry desorption experiment (TranDeso1). This experiment was conducted in the wet-packed column. Beginning with SCRW, SCRW and SGW-0 were alternately eluted through the column to represent transient chemical conditions in locations adjacent to the Columbia River. In order to isolate the effects of transient chemistry, as in the first experiment, flow was in one direction at a constant rate. Two stop-flow events (with lengths of 96 and 99 h) were conducted to evaluate desorption kinetics when the column was saturated by SCRW and SGW.

[16] After completing all desorption experiments, a conservative $(\mathrm{Br})$ tracer addition was conducted in each column to obtain physical transport parameters. The $\mathrm{Br}$ breakthrough curve was fitted using STAMMT-L [Haggerty and Reeves, 2002] to estimate the fraction of immobile pore domain and the corresponding first-order mass transfer coefficient.

\subsection{Analytical Methods}

[17] U(VI) was measured in a kinetic-phosphorescence analyzer (KPA-11, Chemchek Instruments, Richland, WA) after dilution with $0.1 \mathrm{M} \mathrm{HNO}_{3}$. Major anions and $\mathrm{Br}$ were measured using an ion chromatograph (Dionex ICS-2000); major cations were measured by ICP-OES (iCAP-5000 Thermo Scientific, Waltham, MA); alkalinity was measured with both Titerts test kits (CHEMetrics, Calverton, VA) as well as titrations by hand with $0.02 \mathrm{~N} \mathrm{H}_{2} \mathrm{SO}_{4}$.

\subsection{Numerical Modeling}

[18] As a first step, the results of the batch experiments were employed to develop a generalized composite U(VI) surface complexation model [e.g., Davis et al., 1998; Bond et al., 2008] for the sediment utilized in our experiments. Equilibrium constants for surface complexation reactions were obtained by nonlinear, least squares optimization as described by Herbelin and Westall [1999]. The measured chemical composition for each experimental data point was included in the computation, and $\mathrm{U}(\mathrm{VI})$ aqueous speciation was computed using the constants in Table 2. Absolute errors in concentrations were set to zero. Relative errors were as follows: $1.0 \%$ for site concentration, $2.0 \%$ for major cation and anion concentrations, $3.0 \%$ for $\mathrm{U}(\mathrm{VI})$ concentration, and $5.0 \%$ for hydrogen ion and $\mathrm{H}_{2} \mathrm{CO}_{3}$ concentrations. This procedure is consistent with those used previously for surface complexation model fitting to adsorption of metal ions on natural materials [Davis et al., 1998; Bond et al., 2008].

[19] In a second step, the reactive transport model PHT3D [Prommer et al., 2003], a coupling of the multispecies transport model MT3DMS [Zheng and Wang, 1999], and the geochemical reaction model PHREEQC-2 [Parkhurst and Appelo, 1999] was extended for the multirate surface complexation model proposed by Liu et al. [2008] and subsequently used to simulate the U(VI) adsorption/ desorption in column experiments. The reactions in Table 2 and the newly derived surface complexion reaction (described below) were added in the standard PHREEQC-2 thermodynamic database [Parkhurst and Appelo, 1999]. As by Liu et al. [2008], precipitation/dissolution was not modeled. This is primarily based on the spectroscopic [Catalano et al., 2006] and chemical extraction results [Bond et al., 2008] showing that most $\mathrm{U}(\mathrm{VI})$ in the 300 Area smear zone exists as adsorbed species. Moreover, Liu et al. [2006] 
Table 2. Aqueous U(VI) Speciation Reactions

\begin{tabular}{|c|c|}
\hline U Reactions & $\log K$ \\
\hline $\mathrm{UO}_{2}^{2+}+\mathrm{H}_{2} \mathrm{O}=\mathrm{UO}_{2} \mathrm{OH}^{+}+\mathrm{H}^{+}$ & $-5.25^{\mathrm{a}}$ \\
\hline $\mathrm{UO}_{2}^{2+}+2 \mathrm{H}_{2} \mathrm{O}=\mathrm{UO}_{2}(\mathrm{OH})_{2}+2 \mathrm{H}^{+}$ & $-12.15^{\mathrm{a}}$ \\
\hline $\mathrm{UO}_{2}^{2+}+3 \mathrm{H}_{2} \mathrm{O}=\mathrm{UO}_{2}(\mathrm{OH})_{3}^{-}+3 \mathrm{H}$ & $-20.25^{\mathrm{a}}$ \\
\hline $\mathrm{UO}_{2}^{2+}+4 \mathrm{H}_{2} \mathrm{O}=\mathrm{UO}_{2}(\mathrm{OH})_{4}^{2-}+4 \mathrm{H}$ & $-32.40^{\mathrm{a}}$ \\
\hline $2 \mathrm{UO}_{2}^{2+}+\mathrm{H}_{2} \mathrm{O}=\left(\mathrm{UO}_{2}\right)_{2}(\mathrm{OH})^{3+}+\mathrm{H}^{+}$ & $-2.70^{\mathrm{a}}$ \\
\hline $2 \mathrm{UO}_{2}^{2+}+2 \mathrm{H}_{2} \mathrm{O}=\left(\mathrm{UO}_{2}\right)_{2}(\mathrm{OH})_{2}^{2+}+2 \mathrm{H}^{+}$ & $-5.62^{\mathrm{a}}$ \\
\hline $3 \mathrm{UO}_{2}^{2+}+4 \mathrm{H}_{2} \mathrm{O}=\left(\mathrm{UO}_{2}\right)_{3}(\mathrm{OH})_{4}^{2+}+4 \mathrm{H}^{+}$ & $-11.90^{\mathrm{a}}$ \\
\hline $3 \mathrm{UO}_{2}^{2+}+5 \mathrm{H}_{2} \mathrm{O}=\left(\mathrm{UO}_{2}\right)_{3}(\mathrm{OH})_{5}^{+}+5 \mathrm{H}^{+}$ & $-15.55^{\mathrm{a}}$ \\
\hline $3 \mathrm{UO}_{2}^{2+}+7 \mathrm{H}_{2} \mathrm{O}=\left(\mathrm{UO}_{2}\right)_{3}(\mathrm{OH})_{7}^{-}+7 \mathrm{H}^{+}$ & $-32.20^{\mathrm{a}}$ \\
\hline $4 \mathrm{UO}_{2}^{2+}+7 \mathrm{H}_{2} \mathrm{O}=\left(\mathrm{UO}_{2}\right)_{4}(\mathrm{OH})_{7}^{+}+7 \mathrm{H}^{+}$ & $-21.90^{\mathrm{a}}$ \\
\hline $\mathrm{UO}_{2}^{2+}+\mathrm{CO}_{3}^{2-}=\mathrm{UO}_{2} \mathrm{CO}_{3}$ & $9.94^{\mathrm{a}}$ \\
\hline $\mathrm{UO}_{2}{ }^{2+}+2 \mathrm{CO}_{3}{ }^{2-}=\mathrm{UO}_{2}\left(\mathrm{CO}_{3}\right)_{2}^{2-}$ & $16.61^{\mathrm{a}}$ \\
\hline $\mathrm{UO}_{2}{ }^{2+}+3 \mathrm{CO}_{3}{ }^{2-}=\mathrm{UO}_{2}\left(\mathrm{CO}_{3}\right)_{3}^{4-}$ & $21.84^{\mathrm{a}}$ \\
\hline $3 \mathrm{UO}_{2}{ }^{2+}+6 \mathrm{CO}_{3}{ }^{2-}=\left(\mathrm{UO}_{2}\right)_{3}\left(\mathrm{CO}_{3}\right)_{6}^{6-}$ & $54^{\mathrm{a}}$ \\
\hline $2 \mathrm{UO}_{2}{ }^{2+}+\mathrm{CO}_{3}{ }^{2-}+3 \mathrm{H}_{2} \mathrm{O}=\left(\mathrm{UO}_{2}\right)_{2}\left(\mathrm{CO}_{3}\right)(\mathrm{OH})_{3}^{-}+3 \mathrm{H}^{+}$ & $-0.855^{\mathrm{a}}$ \\
\hline $3 \mathrm{UO}_{2}{ }^{2+}+\mathrm{CO}_{3}{ }^{2-}+3 \mathrm{H}_{2} \mathrm{O}=\left(\mathrm{UO}_{2}\right)_{3} \mathrm{O}(\mathrm{OH})_{2}\left(\mathrm{HCO}_{3}\right)^{+}+3 \mathrm{H}^{+}$ & $0.655^{\mathrm{a}}$ \\
\hline $11 \mathrm{UO}_{2}{ }^{2+}+6 \mathrm{CO}_{3}{ }^{2-}+12 \mathrm{H}_{2} \mathrm{O}=\left(\mathrm{UO}_{2}\right)_{11}\left(\mathrm{CO}_{3}\right)_{6}(\mathrm{OH})_{12}^{2-}+12 \mathrm{H}^{+}$ & $36.43^{\mathrm{a}}$ \\
\hline $2 \mathrm{Ca}^{2+}+\mathrm{UO}_{2}{ }^{2+}+3 \mathrm{CO}_{3}{ }^{2-}=\mathrm{Ca}_{2} \mathrm{UO}_{2}\left(\mathrm{CO}_{3}\right)_{3}$ & $30.70^{\mathrm{b}}$ \\
\hline $\mathrm{Ca}^{2+}+\mathrm{UO}_{2}{ }^{2+}+3 \mathrm{CO}_{3}^{2-}=\mathrm{CaUO}_{2}\left(\mathrm{CO}_{3}\right)_{3}^{2-}$ & $27.18^{\mathrm{b}}$ \\
\hline $\mathrm{Mg}^{2+}+\mathrm{UO}_{2}{ }^{2+}+3 \mathrm{CO}_{3}{ }^{2-}=\mathrm{MgUO}_{2}\left(\mathrm{CO}_{3}\right)_{3}^{2-}$ & $26.11^{\mathrm{b}}$ \\
\hline $\mathrm{UO}_{2}{ }^{2+}+\mathrm{NO}_{3}^{-}=\mathrm{UO}_{2} \mathrm{NO}_{3}^{+}$ & $0.3^{\mathrm{b}}$ \\
\hline $\mathrm{UO}_{2}^{2+}+\mathrm{Cl}^{-}=\mathrm{UO}_{2} \mathrm{Cl}^{+}$ & $0.17^{\mathrm{a}}$ \\
\hline $\mathrm{UO}_{2}^{2+}+2 \mathrm{Cl}^{-}=\mathrm{UO}_{2} \mathrm{Cl}_{2}$ & $-1.1^{\mathrm{a}}$ \\
\hline $\mathrm{UO}_{2}{ }^{2+}+\mathrm{SO}_{4}{ }^{2-}=\mathrm{UO}_{2} \mathrm{SO}_{4}$ & $3.15^{\mathrm{a}}$ \\
\hline $\mathrm{UO}_{2}^{2+}+2 \mathrm{SO}_{4}^{2-}=\mathrm{UO}_{2}\left(\mathrm{SO}_{4}\right)_{2}^{2-}$ & $4.14^{\mathrm{a}}$ \\
\hline
\end{tabular}

${ }^{\mathrm{a}}$ Guillaumount et al. [2003].

${ }^{\mathrm{b}}$ Dong and Brooks [2006].

shows that the dissolution of precipitated U(VI) has a halflife of 1 week to 5 months depending on the solution chemistry and mass transfer characteristics. This indicates that $\mathrm{U}(\mathrm{VI})$ dissolution does not play an essential role within the time frame used in the column experiments. In addition, the low U(VI) concentration observed in the experiments does not likely cause any precipitation. Partial pressure of $\mathrm{CO}_{2}$ in the model is assumed to be $3.2 \times 10^{-4} \mathrm{~atm}$.

[20] The dual domain, multirate model has been used in several previous studies [Liu et al., 2008; Ma et al., 2010; Greskowiak et al., 2010]. It is modified from Qafoku et al.'s [2005] model:

$$
\begin{gathered}
\theta_{m} \frac{a c_{i}^{m}}{\partial t}+\theta_{m} \sum_{J=1}^{M_{i}}\left[\alpha_{i j} \sum_{k=1}^{M D} \frac{\partial m_{j}^{k, m}}{\partial t}\right] \\
=\theta_{m} D \frac{\partial^{2} c_{i}}{a x^{2}}-\theta_{m} v \frac{\partial c_{i}}{\partial x}-\omega \theta_{i m}\left(C_{i}^{m}-C_{i}^{i m}\right), \\
\frac{\partial m_{j}^{k, m}}{\partial t}=\alpha_{k}\left(\mathrm{Q}_{\mathrm{j}}^{\mathrm{m}}-m_{j}^{k, m}\right), \\
\frac{a c_{i}^{i m}}{\partial t}+\sum_{j=1}^{M i}\left[\alpha_{i j} \sum_{k=1}^{M D} \frac{\partial m_{j}^{k, j m}}{\partial t}\right]=\omega\left(C_{i}^{m}-C_{i}^{i m}\right), \\
\frac{\partial m_{j}^{k, i m}}{\partial t}=\alpha_{k}\left(\mathrm{Q}_{\mathrm{j}}^{\mathrm{im}}-m_{j}^{k, i m}\right),
\end{gathered}
$$

where $\theta_{m}$ and $\theta_{i m}$ are the volumetric fraction associated with the mobile and immobile domains; $C_{i}^{m}$ and $C_{i}^{i m}$ are the aqueous concentrations of chemical component $i$ in the mobile and immobile domains, respectively; $m_{j}^{k, m}$ and $m_{j}^{k, i m}$ are the concentrations of adsorbed species $j$ at adsorption domain $k$ in the mobile and immobile domains, respectively; $a_{i j} i$ is the stoichiometric coefficient of chemical component $i$ in adsorbed species $j ; D$ is the dispersion coefficient; $a_{k}$ is the first-order rate constant at adsorption site $k$ and in our case follows a lognormal distribution; $Q_{j}^{m}$ and $\mathrm{Q}_{\mathrm{j}}^{\text {im }}$ are the equilibrium adsorption concentrations of adsorbed species $j$ in the mobile and immobile domains, respectively; $\omega$ is the first-order mass transfer coefficient between the mobile and immobile domains; $M i$ is the number of adsorbed species containing chemical component $i$; and $M D$ is the total number of adsorption domains.

[21] The lognormal density of first-order rate constants $\alpha$ [e.g., Pedit and Miller, 1994; Culver et al., 1997; Haggerty and Gorelick, 1998] is

$$
p(\alpha)=\frac{1}{\alpha \sigma \sqrt{2 \pi}} \exp \left[-\frac{1}{2 \sigma^{2}}(\ln (\alpha)-\mu)^{2}\right],
$$

where $p$ is the probability density of a site that has a rate constant of $\alpha ; \mu$ and $\sigma$ are the mean and standard deviation. Recent studies [Liu et al., 2008; Greskowiak et al., 2010] used 50 discrete adsorption domains $(M D=50)$ to conduct the simulations.

[22] In the simulation with dual domain, each of the 50 adsorption sites in the mobile domain and each of the 50 adsorption sites in the immobile domain were assigned the same surface site density. The initial adsorbed U(VI) concentration at each site was also assigned the same value according to the labile $\mathrm{U}(\mathrm{VI})$ in the sediment (adsorbed $\mathrm{U}(\mathrm{VI})$ ). Both site density and U(VI) concentration were normalized to porosities (Table 3) and have units of mol/

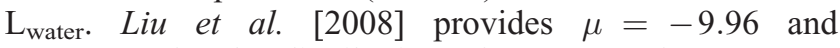
$\sigma=2.68$ for the distribution of mass transfer rate constants. We use this as the starting point in our simulation and calibrate it according to the column data. The initial water composition in both mobile and immobile domain were set equal to the first samples collected. The initial $\mathrm{U}(\mathrm{VI})$ concentration before packing was set as zero.

\section{Results and Discussion}

\subsection{Batch Experiments}

[23] In each batch reactor, initial aqueous U(VI) concentrations increased rapidly in the first $1-3$ days. Subsequently, for experiments conducted at suspension densities of $1000 \mathrm{~g} / \mathrm{L}, \mathrm{U}(\mathrm{VI})$ continued to increase out to 15 days and then remained relatively constant for the duration of the experiment, which was 293 days. In contrast, for the experiments conducted at suspension densities of $100 \mathrm{~g} / \mathrm{L}, \mathrm{U}(\mathrm{VI})$ concentrations increased through the experiment. After 293 days, $95 \%-100 \%$ of the labile U(VI) had desorbed.

[24] Changes in U(VI) concentrations were accompanied by compositional changes that influence U(VI) adsorption equilibrium. Most importantly for the derivation of the surface-complexation model, alkalinity increased 10\%-20\% in the first 7 days of all batch experiments after which higher solid-to-liquid ratio $(1000 \mathrm{~g} / \mathrm{L})$ systems stabilized and those at lower solid-to-liquid ratio $(100 \mathrm{~g} / \mathrm{L})$ continued to increase at a slower rate. The $\mathrm{pH}$ of $1000 \mathrm{~g} / \mathrm{L}$ reactors 
Table 3. Physical Properties of Two Columns

\begin{tabular}{lcc}
\hline & $\begin{array}{c}\text { Column 1 } \\
\left(\text { Deso 1 }^{\mathrm{a}}\right)\end{array}$ & $\begin{array}{c}\text { Column 2 } \\
\left(\text { TranDeso 1 }^{\mathrm{b}}\right)\end{array}$ \\
\hline Total sediment $(\mathrm{g})$ & 1821.9 & 1741.9 \\
Total porosity & 0.333 & 0.377 \\
Dispersivity $(\mathrm{cm})$ & 9.77 & 13.0 \\
Porosity ratio $\left(\theta_{\text {im }} / \theta_{m}\right)$ & 0.2 & 0 \\
First-order mass transfer rate $(1 / \mathrm{h})$ & 0.115 & $\mathrm{~N} / \mathrm{A}$ \\
\hline
\end{tabular}

${ }^{a}$ Deso 1: desorption experiment with constant chemistry influent.

${ }^{\mathrm{b}}$ TranDeso 1: desorption experiment with transient chemistry influent.

decreased by 0.4 over the first 3 days and then slowly increased 0.6 units for the remaining 290 days. At $100 \mathrm{~g} / \mathrm{L}$, $\mathrm{pH}$ generally dropped by 0.1 units and then increased by 0.2 on a similar time scale. Ca concentrations followed trends similar to U(VI). These changes are consistent with slow aerobic respiration and incongruent dissolution of aluminosilicate minerals typically observed on these time scales [Blum and Stillings, 1995]. The composition changes were reflected in the batch equilibrium-adsorption modeling that was carried out to derive a generalized composite surface complexation model.

[25] Several surface complexation reactions and combinations of reactions proposed by Bond et al. [2008] were tested for their suitability to describe the experimentally observed $\mathrm{U}(\mathrm{VI})$ adsorption over the applicable range of chemical conditions at equilibrium. The best fit was obtained with the reaction

$$
\begin{aligned}
> & \mathrm{SOH}+\mathrm{UO}_{2}{ }^{2+}+2 \mathrm{H}_{2} \mathrm{CO}_{3} \\
& =>\mathrm{SOUO}_{2}\left(\mathrm{CO}_{3} \mathrm{HCO}_{3}\right)^{2-}+4 \mathrm{H}^{+} .
\end{aligned}
$$

[26] Assuming an adsorption site density of $3.84 \mu \mathrm{mol} / \mathrm{m}^{2}$ [Davis and Kent, 1990], the best-fit $\log (K)$ value was -11.73 and weighted sum of squares divided by degrees of freedom (WSOS/DF) was 2.8 .

[27] This model accounted for the influence of variable chemistry on U(VI) adsorption over the compositional range applicable to the site (Figure 2). Actual model-calculated $K_{d}$ values showed scatter similar to the scatter in the experimentally measured values. This is a result of differences in chemical composition (e.g., Ca concentration) other than alkalinity that influence U(VI) adsorption. Dissolved U(VI) concentrations computed with this surface complexation model and aqueous concentrations observed at each time point showed that equilibrium with respect to U(VI) adsorption was achieved within 42 days, after which U(VI) adsorption remained at equilibrium as chemical conditions continued to evolve.

\subsection{Column Experiments}

\subsubsection{Constant Influent Desorption Experiment}

[28] Major ion concentrations decreased rapidly within the first few pore volumes (PV) and then remained relatively constant at a level close to the injected SGW-0 during the Deso1 experiment (Figure 3a). The rapid decrease is likely to be a result of the dissolution of salts that had precipitated prior to the experiment during sediment drying, and/or reequilibration of ions on the exchange sites. These processes likely contributed to observed decreases in alkalinity and $\mathrm{pH}$ (Figure $3 b$ ). After the first 3 to 4 pore volumes, the chemical composition of the effluent changed much more slowly. A

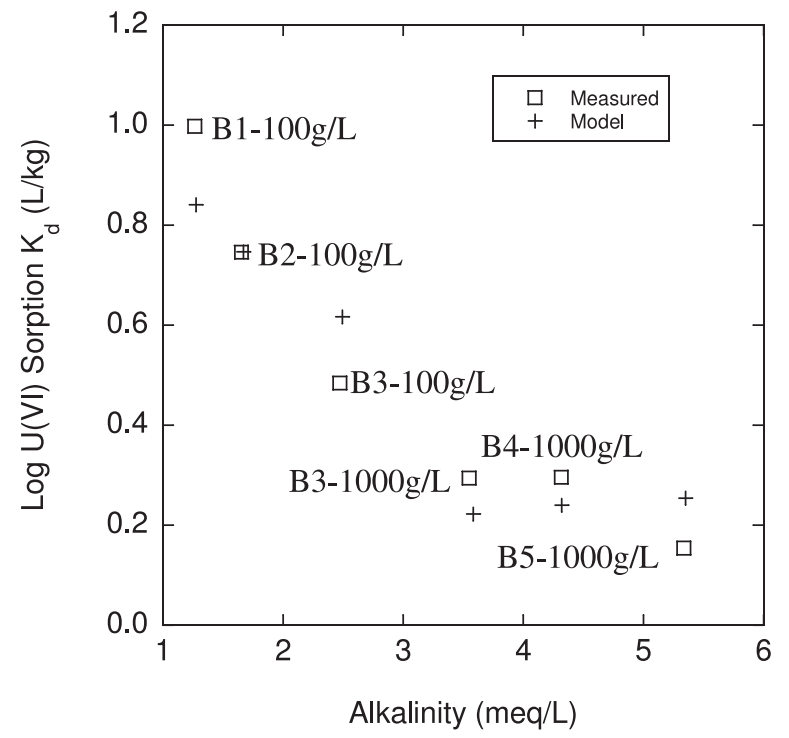

Figure 2. Experimentally measured and model-calculated equilibrium adsorbed [U(VI)] plotted against alkalinity.

significant drop in $\mathrm{NO}_{3}^{-}$concentration was observed during all three stop-flow events. After the stop flow, $\mathrm{NO}_{3}^{-}$quickly increased back to the influent concentration $0.5 \mathrm{mmol} / \mathrm{L}$. The observed loss of $\mathrm{NO}_{3}^{-}$during stop-flow events was likely caused by denitrification, suggesting active microbial respiration occurred during the experiments. Microbial respiration likely also contributed to increases in alkalinity observed during the first two stop-flow events. In turn, increases in alkalinity during stop-flow events could contribute to U(VI) desorption (Figure 2). The pH slowly decreased until the second stop-flow event (Figure 3b), after which it dropped 0.5 unit and remained relatively constant thereafter. In addition to microbial respiration, slow release of hydrogen ions from adsorption and exchange sites may also contribute to the observed decrease of $\mathrm{pH}$ in the column [Liu et al., 2009]. Minor increases in Ca concentrations were observed after the second and third stop-flow events (Figure 3a). It is possibly caused by calcite dissolution during the stop flow associated with $\mathrm{pH}$ decrease.

[29] Trends in U(VI) desorption are similar to those reported previously for vadose-zone U(VI)-contaminated sediments from the site [e.g., Mason et al., 1997; Qafoku et al., 2005; Liu et al., 2008], with an initial rapid decline in $\mathrm{U}(\mathrm{VI})$ followed by a long tail (Figure 4a). Changes in chemistry favoring desorption based on equilibrium calculations were observed (e.g., increased alkalinity and $\mathrm{Ca}^{2+}$ ) during the stop-flow events. The slow approach to equilibrium observed in batch experiments suggests that U(VI) desorption equilibrium is not likely to be reached within the time scale of the column experiments. Thus, the observed increases in $\mathrm{U}(\mathrm{VI})$ concentrations provide further evidence for rate-limited U(VI) desorption. In the context of the multirate surface complexation model, during the stop flow, the sites at the faster end of the rate-coefficient distribution become populated with the U(VI) released from sites at the slower end of the distribution [Liu et al., 2008]. The increased U(VI) concentration after the stop flow is attributed to this redistribution. The increase of the U(VI) concentration is very small in the third stop-flow event 



Figure 3. Chemical composition of effluent in the experiment Desol.

(Figure 4a). This likely results from depletion of sorbed U(VI) during the 17 day period prior to the third stop-flow event. A mass balance calculation shows that by the beginning of the third stop-flow event, nearly $40 \%$ of the sorbed $\mathrm{U}(\mathrm{VI})$ had been removed.

\subsubsection{Transient Chemistry Desorption Experiment}

[30] Significant decreases in dissolved salt concentrations and other chemical conditions were observed during the first 3 pore volumes in TransDeso1, similar to what was observed in Desol (Figure 5). These changes in chemical composition likely reflect the same set of processes described in the previous section. Subsequently, over the following 10 pore volumes, changes in major ion concentrations steadily approached those expected based on changes in the influent concentrations (Figure 5b). Measured $\mathrm{pH}$ values constantly increased for the first 3 pore volumes, after which they decreased and then increased close to the $\mathrm{pH}$ in SGW-0 from
3 to 5 PV (Figure 5a). Subsequent to the first stop-flow event, changes in effluent $\mathrm{pH}$ values followed trends in the influent $\mathrm{pH}$, but the low $\mathrm{pH}$ values characteristic of SCRW were never fully achieved (Figure 5a). These trends in $\mathrm{pH}$ values likely reflect differences in alkalinity in the influent solutions. The alkalinity of the SCRW is likely too low to counteract the $\mathrm{pH}$-buffer capacity of sediment surfaces. In addition, the low alkalinity, $\mathrm{pH}$ values, and $\mathrm{Ca}^{2+}$ concentration of SCRW create chemical conditions near the inlet where calcite is undersaturated. Dissolution of calcite results in an increase in alkalinity during transport through the column. A similar set of reactions should occur as Columbia River water is transported through the aquifer at elevated river stages. Similar to the second stop-flow event in Deso1, there was a $0.13 \mathrm{pH}$ unit drop during the stop-flow event 1 and $0.2 \mathrm{pH}$-unit drop during the stop-flow event 2 . Likewise, the increased alkalinities were 0.38 and $0.43 \mathrm{meq} / \mathrm{L}$, respectively. 

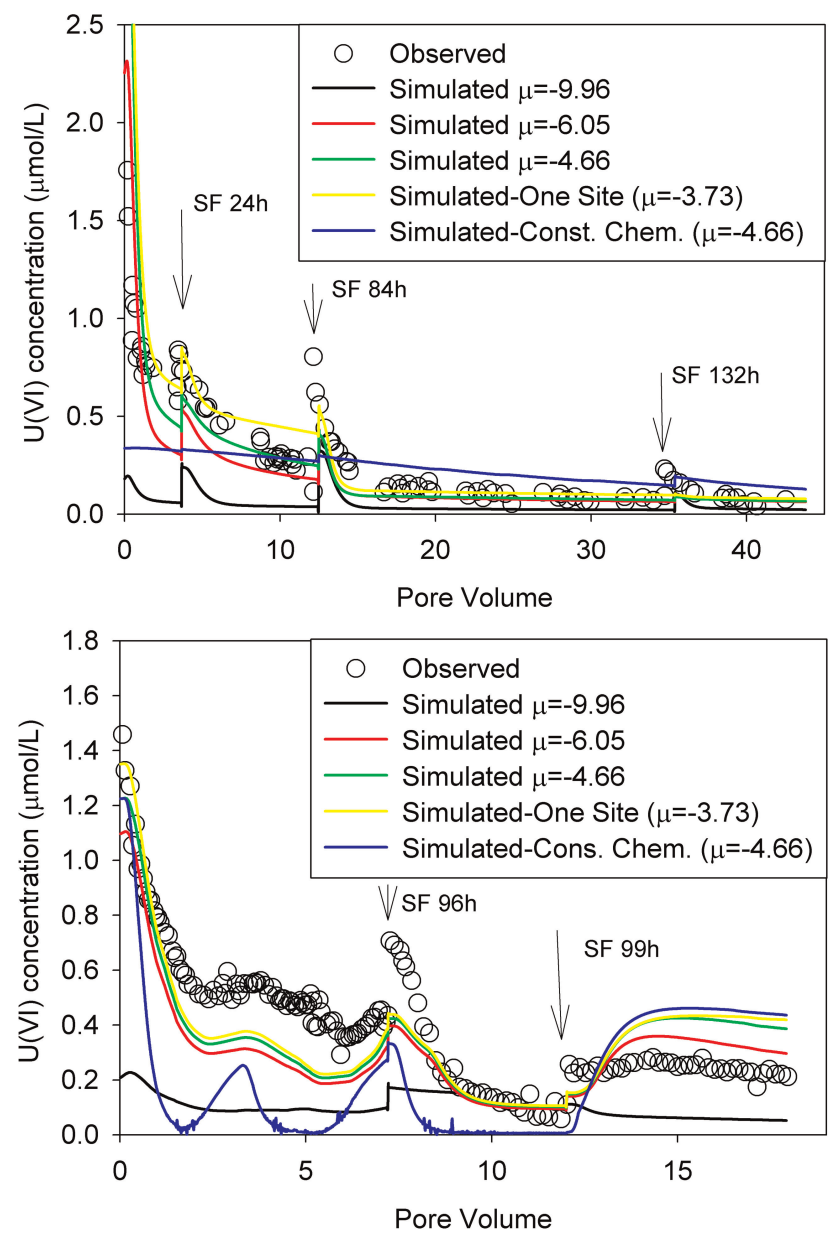

Figure 4. Observed and simulated U(VI) desorption in two column experiments.

[31] U(VI) concentrations decreased much more slowly during TransDesol than was observed during Desol (Figure 4). Even though the chemical composition of injection SCRW changed during transport through the column, the effluent chemical conditions exhibited lower $\mathrm{pH}$, alkalinity, and $\mathrm{Ca}^{2+}$ concentrations than those observed during injection of SGW-0. Thus, during periods when SCRW was injected into the column, chemical conditions favored significant decreases in U(VI) desorption throughout the column. Rate-limited U(VI) desorption was observed during the two stop-flow events (Figure 4b). The significantly smaller increase in $\mathrm{U}(\mathrm{VI})$ concentrations observed during the second stop-flow event as compared to the first also reflects differences in the aqueous chemistry resident in the column during the stop-flow events. During the first and second stop-flow events, aqueous chemistry reflected the composition of SGW and SCRW, respectively, as modified by the additional chemical reactions and biological processes described previously. Lower alkalinity values and $\mathrm{Ca}^{2+}$ concentrations during the second stop flow were less favorable to U(VI) desorption (Figure 2) and therefore less extensive mass transfer of $\mathrm{U}(\mathrm{VI})$ out of the sediments occurred.

\subsection{Modeling}

[32] The physical transport parameters of the two column experiments were estimated with the code STAMMT-L and the results are given in Table 3. In contrast to the experiment Deso1, no immobile domain needed to be considered to fit the $\mathrm{Br}$ breakthrough curve in the experiment TranDeso1 where the sediment was wet packed. Preferential flows might occur along the column wall during the experiments. Therefore, in optimization, longitudinal dispersivity was optimized to a large value to simulate the observed breakthrough curve.

[33] Modeling the temporal variation in effluent chemistry would require ad hoc assumptions about mineral dissolution and other reactions that affected $\mathrm{pH}$, cation, and carbonate concentrations. Instead, we adjusted the $\mathrm{pH}$, alkalinity, and other major cations of the influent SGW-0 and SCRW manually to the corresponding values observed in the effluent in both experiments. In Deso1, considering that the measured chemistry was relatively stable except in the first few pore volumes, averaged values of $\mathrm{pH}$ and alkalinity just before and just after the three stop-flow events were used to make four SGW recipes used in the model (SGW1-SGW4). In TranDeso1, a more detailed chemical composition sequence was used to investigate the responses of $\mathrm{U}(\mathrm{VI})$ desorption to variations in water chemistry. Twenty one discrete chemical compositions based on the $\mathrm{pH}$, alkalinity, and major ion composition of the effluent were used as input in the model. Therefore the influent chemistry approximately resembled the evolutions of the 



Figure 5. Selected chemical compositions in influent and effluent in TranDesol.

effluent chemistry and most of the compositional transitions in the column were thereby manually captured. Model calibration was carried out by only adjusting the rate constant distribution with the condition that the log-standard deviation had to be the same as measured by Liu et al. [2008]. An additional simulation using a single fast rate constant $\left(0.0241 \mathrm{~h}^{-1}\right)$ was conducted to evaluate whether the number of discrete adsorption domains could be reduced.

[34] The calibrated model captured the major trends in U(VI) concentrations as observed in both experiments (Figure 4). In Deso1, increasing the log mean of rate constant increased the overall U(VI) desorption. However, the influence of the rate constant decreased when the mean of the rate constants became sufficiently large that the model- calculated U(VI) concentrations approached equilibrium. Under such conditions, U(VI) desorption was mainly controlled by the pore water chemistry rather than the rate constant distribution. Simulations using a single constant rate showed no significant differences than the simulations using 50 discrete rate constants, suggesting that a single adsorption domain may sufficiently represent the early stage U(VI) desorption in this composite sediment. However, as shown in Figure 4a, the increased U(VI) in the third stop-flow event was completely missed in the single-rate simulation case. Almost all the simulation cases captured the magnitude of the U(VI) increase in the first stop-flow event but underestimated the U(VI) increase in the second stop-flow event and missed the U(VI) increase in the third stop-flow event. This indicates that a small amount of U(VI) on slow adsorption sites remained in the sediment. Models with additional complexity, such as those with a relatively large portion of faster adsorption sites and a small portion of slow adsorption sites, might be required to improve predicted U(VI) desorption. Utilizing the best-fit simulation with a $\log$ mean of $\mu=$ -4.66 , an additional simulation has been carried out that does not take into account the chemical variation induced by mineral dissolution and ion exchange reactions within the column; instead, the experimentally defined (constant) input solution was employed. The simulation results show a nearly constant U(VI) desorption through time (Figure 4a). 
Therefore it can be concluded that without considering the changes of major ion chemistry occurring within the column, U(VI) desorption cannot be adequately described in Deso1.

[35] Similar to Deso1, simulated results of TransDeso1 could not be significantly improved by increasing the mean of rate constants (Figure 4b) when $\mu>=-6.05$. Differences between simulation cases became even less significant during the SCRW injection phases. For example, the various cases produced essentially identical calculated aqueous U(VI) concentration differences between 9 and 12 pore volumes. The simulation differences, however, increased during 12 and $18 \mathrm{PV}$ when the pore solution generates less adsorption strength. Comparison of the 50 domain simulations where $\mu \geq-6.05$ and the single adsorption domain simulation again indicates that a single kinetic rate constant may be sufficient to represent the results of these experiments. Note that in the single-rate simulation case, the lack of slow adsorption domains (as seen in Deso1) was not significant because of the relatively short contact times between pore fluids and sediments. Because the input solutions have been adjusted to closely track the compositional changes occurring within the column, the overall underestimation of U(VI) concentration between 2 and 7 PV is likely to be result of the inherent error of the surface complexation model that overestimates the adsorption strength around an alkalinity of $2 \mathrm{meq} / \mathrm{L}$ (Figure 2). However, the small undulations resulting from the variable major ion chemistry were well captured by the model. Without adapting the input solutions (i.e., neglecting the effect of sediment buffering) in the simulation for $\mu=-4.66$, simulated U(VI) concentrations drastically underestimate the measured $\mathrm{U}(\mathrm{VI})$ concentrations with those simulated with the adapted inflow solution. The response of U(VI) concentrations to the water chemistry changes in the nonadapted simulation was more pronounced than in the simulation where the inflow solution was adapted (Figure $4 b$ ), even though concentrations were overall low. Again, this means that without accounting for the water chemistry changes occurring along the column, U(VI) desorption could not be predicted. In both stop-flow events, all simulation cases underestimated the U(VI) increase. This discrepancy may result from the assumption of constant chemical conditions spatially within the column. This assumption is most likely to be violated during stop-flow events, where chemical reaction rates likely drive differences in chemical composition spatially along the column. During the stop flow, the chemical composition in the column is likely to favor desorption, but the composition near the column outlet (measured in the first effluent sample following the stop flow) favors adsorption. None of the simulations could account for the enhanced desorption during two stop-flow events and it could not be clarified to what degree chemistry changes or mass transfer processes are responsible for the observed U(VI) concentration peaks.

\section{Conclusion}

[36] The U(VI) transport at the Hanford 300 Area is affected by factors expected to be important in many sites near streams and rivers. These include variable chemical composition owing to changes in flow direction caused by changes in river stage, and slow mass transfer owing to dif- fusion and adsorption in mineral grains and mineral-grain aggregates. In the present study, laboratory experiments and corresponding numerical modeling have been carried out to investigate U(VI) adsorption/desorption behavior and its dependency on transient water chemistry conditions that are representative of, but not limited to, the Hanford 300 Area site. The results of laboratory batch and column experiments demonstrate the importance of $\mathrm{pH}$, (bi)carbonate concentration (measured as the alkalinity), and $\mathrm{Ca}^{2+}$ concentrations on U(VI) adsorptive mass transfer. A previously proposed multicomponent multirate surface complexation model only captured the $\mathrm{U}(\mathrm{VI})$ desorption in the conducted column experiments when chemical conditions were adequately defined. However, in the studied sediment and within the time scale of the column experiments, the number of adsorption domains could be decreased to increase the computational efficiency. Under constant water chemistry, desorption of $\mathrm{U}(\mathrm{VI})$ is fully controlled by rate-limited mass transfer, and the underestimation of U(VI) increase in the stop-flow event at the later stage of the experiment (e.g., in Deso1) could be compensated by assigning several slower adsorption domains to retard the desorption. In the experiments with transient chemistry, U(VI) adsorption/desorption was largely controlled by the rate of changes in water chemistry rather than the mass transfer rates.

[37] From this study, it can be concluded that the application of the multirate surface complexion model to the field is feasible when the groundwater chemistry is sufficiently constrained or the evolution of the groundwater chemistry can be accurately predicted. However, the rate constant distributions and the number of the adsorption domains should be carefully calibrated to characterize the physical and chemical properties and the contamination history of the investigated sediments. At the Hanford 300 Area, near the Columbia River, stage oscillations and microbial metabolism change the water chemistry on a daily and seasonal basis. The field measurements of U(VI) therefore have to be coupled with chemistry measurements to constrain the hydrochemical parameters of the model. It will be valuable to improve models for predicting the evolution of inorganic carbon, major cations, and $\mathrm{pH}$ under transient chemical boundary conditions.

[38] Acknowledgments. This research was supported by the U.S. DOE Office of Biological and Environmental Research, Environmental Remediation Science Program (ERSP) though DOE-ERSP grant DE-FG0206ER06-16 as part of the Hanford 300 Area Integrated Field Research Challenge Project. Funding to J.G. was provided by a postdoctoral fellowship from CSIRO OCE. We also would like to thank Brian Wood for the use of equipment, Stephanie Harrington for help with experimental setup, and Chongxuan Liu for helpful conversations and ideas. Special thanks to Chunmiao Zheng and Rui Ma for providing the PHT3D program. Reviews by Mike Hay, Rob Runkel, and three anonymous reviewers greatly improved the quality of the manuscript. Use of brand names is for identification purposes only and does not present endorsement by the U.S. Geological Survey.

\section{References}

Blum, A. E., and L. L. Stillings (1995), Feldspar dissolution kinetics, in Reviews in Mineralogy and Geochemistry, edited by A. F. White and S. L. Brantley, vol. 31, pp. 291-351, Mineralogical Society of America, Washington, DC

Bond, D. L., J. A. Davis, and J. M. Zachara (2008), Uranium(VI) release from contaminated vadose zone sediments: Estimation of potential 
contributions from dissolution and desorption, in Adsorption of Metals to Geomedia II, edited by M.O. Barnett and D. B. Kent, chap. 14, pp. $375-$ 416, Elsevier, Amsterdam, Netherlands.

Catalano, J. G., J. P. Mckinley, J. M. Zachara, S. C. Smith, and G. E. J. Brown (2006), Changes in uranium speciation through a depth sequence of contaminated Hanford sediment, Environ. Sci. Technol., 40, 2517-2524.

Conant, B., Jr., J. A. Cherry, and R. W. Gillham (2004), A PCE groundwater plume discharging to a river: Influence of the streambed and near-river zone on contaminant distributions, J. Contam. Hydrol., 73, 249-279.

Crowley, K. D., and J. F. Ahearne (2002), Managing the environmental legacy of U.S. nuclear-weapons production, Am. Sci., 90, 514-523.

Culver, T. B., S. P. Hallisey, D. Sahoo, J. J. Deitsch, and J. A. Smith (1997), Modeling the desorption of organic contaminants from long-term contaminated soil using distributed mass transfer rates, Environ. Sci. Technol., 31(6), 1581-1588.

Davis, J. A., and D. B. Kent (1990), Surface complexation modeling in aqueous geochemistry, in Mineral-Water Interface Geochemistry, Reviews in Mineralogy, edited by M. F. Hochella, and A. F. White, pp. 177-260, Mineralogical Society of America, Washington, D. C.

Davis, J. A., J. A. Coston, D. B. Kent, and C. C. Fuller (1998), Application of the surface complexation concept to complex mineral assemblages, Environ. Sci. Technol. 32, 2820-2828.

Davis, J. A., D. E. Meece, M. Kohler, and G. P. Curtis (2004), Approaches to surface complexation modeling of Uranium(VI) adsorption on aquifer sediments, Geochim. Cosmochim. Acta, 68(18), 3621-3641.

Dong, W., and S. C. Brooks (2006), Determination of the formation constants of ternary complexes of uranyl and carbonate with alkaline earth metal $\left(\mathrm{Mg}^{2+}, \mathrm{Ca}^{2+}, \mathrm{Sr}^{2+}\right.$, and $\left.\mathrm{Ba}^{2+}\right)$ using anion exchange method, Environ. Sci. Technol., 40, 4689-4695.

Fritz, B. G., and E. V. Arntzen (2007), Effect of rapidly changing river stage on uranium flux through the hyporheic zone, Ground Water, 45(6), $753-760$.

Greskowiak, J., H. Prommer, C. Liu, V. E. A. Post, R. Ma, C. Zheng, and J. M. Zachara (2010), Comparison of parameter sensitivities between a laboratory and field scale model of uranium transport in a dual domain, distributed-rate reactive system, Water Resour. Res., 46, W09509, doi:10.1029/2009WR008781.

Guillaumount, R., T. Fanghänet, V. Neck, J. Fuger, D. A. Palmer, I. Grenthe, and M. H. Rand (2003), Update on the Chemical Thermodynamics of Uranium, Neptunium, Plutonium, Americium and Technetium, Elsevier, Amsterdam, Netherlands

Haggerty, D. R., and P. Reeves (2002), STAMMT-L 1.0 User's Manual, ERMS \#520308, 76 pp., Sandia National Laboratories, Albuquerque, NM.

Haggerty, R., and S. M. Gorelick (1998), Modeling mass transfer processes in soil columns with pore-scale heterogeneity, Soil Sci. Soc. Am. J., $62(1), 62-74$.

Hammond, G. E., and P. C. Lichtner (2010), Field-scale model for the natural attenuation of uranium at the Hanford 300 Area using high performance computing, Water Resour. Res., 46, W09527 doi:10.1029/2009WR008819.

Hammond, G. E., P. C. Lichtner, R. T. Mills, and C. Lu (2008), Toward petascale computing in geosciences: Application to the Hanford 300 Area, J. Phys. Conf. Ser., 125, 012051 doi:10.1088/1742-6596/125/1/012051.

Herbelin, A. L., and J. C. Westall (1999), FITEQL: A computer program for the determination of chemical equilibrium constants from experimental data, Chemistry Department, Oregon State University, Corvallis, Oregon.

Jacobs, L. A., H. R. von Gunten, R. Keil, and M. Kuslys (1988), Geochemical changes along a river-groundwater infiltration flow path: Glattfelden, Switzerland, Geochim. Cosmochim. Acta, 52(11), 2693-2706.

Kohler, M., D. P. Curtis, D. E. Meece, and J. A. Davis (2004), Methods for estimating adsorbed uranium (VI) and distribution coefficients of contaminated sediments, Environ. Sci. Technol., 38, 240-247.

Lindberg, J. W., and R. E. Peterson (2004), 300-FF-5 operable unit, in Hanford Site Groundwater Monitoring for Fiscal Year 2004, PNNL-15070, edited by M. J. Hartman, L. F. Morasch, and W. D. Webber, pp. 2.12-12.12-31, Pacific Northwest National Laboratory, Richland, Washington.

Liu, C., J. M. Zachara, O. Qafoku, J. P. McKinley, S. M. Heald, and Z. Wang (2004), Dissolution of uranyl microprecipitates from subsurface sediments at Hanford site, USA, Geochim. Cosmochim. Acta, 68(22), 4519-4537.

Liu, C., J. M. Zachara, W. Yantansee, P. D. Majors, and J. P. McKinley (2006), Microscopic reactive diffusion of uranium in the contaminated sediments at Hanford, USA, Water Resour. Res., 42, W12420, doi:10.1029/2006WR005031.

Liu, C., J. M. Zachara, N. P. Qafoku, and Z. Wang (2008), Scale-dependent desorption of uranium from contaminated subsurface sediments, Water Resour. Res., 44, W08413, doi:10.1029/2007WR006478.

Liu, C., Z. Shi, and J. M. Zachara (2009), Kinetics of uranium(VI) desorption from contaminated sediments: Effect of geochemical conditions and model evaluation, Environ. Sci. Technol. 43(17), 6560-6566.

Ma, R., C. Zheng, H. Prommer, J. Greskowiak, C. Liu, J. M. Zachara, and M. L. Rockhold (2010), A field-scale reactive transport model for U(VI) migration influenced by coupled multi-rate mass transfer and surface complexation reactions, Water Resour. Res., 46, W05509, doi:10.1029/ 2009WR008168.

Mason, C. F., W. R. Turney, B. M. Thomson, N. Lu, P. A. Longmire, and C. J. Chisholm-Brause (1997), Carbonate leaching of uranium from contaminated soils, Environ. Sci. Technol., 31(10), 2707-2711, doi:10.1021/es960843j.

McKinley, J. P., J. M. Zachara, C. Liu, S. C. Heald, B. I. Prenitzer, and B. W. Kempshall (2006), Microscale controls on the fate of contaminant uranium in the vadose zone, Hanford Site, Washington, Geochim. Cosmochim. Acta, 70, 1873-1887.

National Research Council (2000), Research Needs in Subsurface Science, U.S. Department of Energy's Environmental Management Science Program, 159 pp., National Academy Press, Washington, DC.

Parkhurst, D., and C. A. J. Appelo (1999), User's guide to PHREEOC (Version 2) - A computer program for speciation, batch-reaction, one-dimensional transport, and inverse geochemical calculations, U.S. Geol. Surv. Water Resour. Invest. Rep. 99-4259.

Pedit, J. A., and C. T. Miller (1994), Heterogeneous sorption processes in subsurface systems. 1. Model formulations and applications, Environ. Sci. Technol., 28(12), 2094-2104.

Prommer, H., D. A. Barry, and C. Zheng (2003), MODFLOW/MT3DMS based reactive multicomponent transport modeling, Ground Water, 41(2), 247-257.

Qafoku, N. P., J. M. Zachara, C. Liu, P. L. Gassman, O. S. Qafoku, and S. C. Smith (2005), Kinetic desorption and sorption of U(VI) during reactive transport in a contaminated Hanford sediment, Environ. Sci. Technol., 39, 3157-3165.

Turner, G. D., J. M. Zachara, J. P. McKinley, and S. C. Smith (1996), Surface charge properties and $\mathrm{UO}_{2}{ }^{2+}$ adsorption of a subsurface smectite, Geochim. Cosmochim. Acta, 60, 3399-3414.

von Gunten, H. R., G. Karametaxas, U. Krähenbuhl, M. Kuslys, R. Giovanoli, E. Hoehn, and R. Keil (1991), Seasonal biogeochemical cycles in riverborne groundwater, Geochim. Cosmochim. Acta, 55(12), $3597-$ 3609

Wellman, D. M., J. M. Zachara, C. Liu, N. P. Qafoku, S. C. Smith, and S. W. Forrester (2008), Advective desorption of Uranium(VI) from contaminated Hanford vadose zone sediments under saturated and unsatureated conditions, Vadose Zone J., 7(4), 1144-1159.

Zachara, J. M., J. A. Davis, C. Liu, J. P. McKinley, N. P. Qafoku, D. M. Wellman, and S. B. Yabusaki (2005), Uranium Geochemistry in Vadose Zone and Aquifer Sediments from the 300 Area Uranium Plume, PNNL15121, Pacific Northwest National Laboratory, Richland, WA.

Zheng, C., and P. Wang (1999), MT3DMS, A modular three-dimensional multi-species transport model for simulation of advection, dispersion and chemical reactions of contaminants in groundwater systems; documentation and user's guide, 202 pp., U.S. Army Engineer Research and Development Center Contract Rep. SERDP-99-1, Vicksburg, MS.

J. D. Greskowiak, CSIRO Land and Water, Private Bag No. 5, Wembley, WA 6913, Australia. (janek.greskowiak@uni-oldenburg.de)

R. Haggerty and J. Yin, Department of Geosciences, Oregon State University, 104 Wilkinson Hall, Corvallis, OR 97331-5506, USA. (jun.yin@ geo.oregonstate.edu; haggertr@geo.oregonstate.edu)

J. D. Istok, Department of Civil Engineering, Oregon State University, 220 Owen Hall, Corvallis, OR 97331-3212, USA. (jack.istok@oregonstate.edu)

D. B. Kent and D. L. Stoliker, U.S. Geological Survey, 345 Middlefield Rd., Menlo Park, CA 94025, USA. (dlstoliker@usgs.gov; dbkent@ usgs.gov)

J. M. Zachara, Pacific Northwest National Laboratory, 3335 Q Ave., K8-96, Richland, WA 99352, USA. (john.zachara@pnl.gov) 